\title{
NOTAS DE JURISPRUDENCIA
}

\section{Tribunal Constitucional (*)}

\begin{abstract}
SUMARIO: I. CONSTITUCIÓN. A. Fuerza normativa. B. Interpretación. II. DERECHOS Y LIBERTADES. A. Derechos fundamentales y libertades públicas. B. Derechos y deberes de los ciudadanos. C. Principios rectores de la política social y económica. D. Garantía y suspensión de estos derechos. III. PRINCIPIOS JURÍDICOS BÁSICOS. IV. INSTITUCIONES DEL ESTADO. A. La Corona. B. Las Cortes Generales. C. El Tribunal Constitucional. D. La Administración Pública. E. El Poder Judicial. V. FUENTES. VI. ORGANIZACIÓN TERRITORIAL DEL ESTADO. A. Comunidades Autónomas. A.1. Autonomía. B.2. Competencias. B. Corporaciones Locales. A.1. Autonomía B.2. Competencias. VII. ECONOMÍA Y HACIENDA. A. Principios generales. B. Presupuestos. C. Organización territorial. D. Tribunal de Cuentas.
\end{abstract}

\section{DERECHOS Y LIBERTADES}

\section{A. Derechos fundamentales y libertades públicas.}

1. Sentencia 85/2003, de 8 de mayo (BOE de 17 de mayo). Ponente: GarcíaCalvo y Montiel y Rodríguez Zapata Pérez (Recursos de amparo electoral acumulados).

Preceptos constitucionales: 14; 16.1; 18.1; 20.1.a); 22.1; 23.1; 23.2; 24.1; 24.2.

otros:

Objeto: Sentencias de la Sala Especial del TS sobre anulación de candidaturas para las elecciones locales y forales de 2003, promovidas por la agrupación de electores Ametzak de Amezketa y otras.

Materias: Principio de igualdad ante la ley; Libertad ideológica; Derecho a la intimidad; Libertad de expresión; Libertad de asociación; Derecho de partici-

(*) Subsección preparada por FRANCISCO ESCRIBANO. 
pación en los asuntos públicos; Acceso en condiciones de igualdad a las funciones y cargos públicos; Derecho a la tutela judicial efectiva; Garantías procesales.

Supuesta la inusitada extensión de la Sentencia, renunciamos a realizar un resumen de la misma. Existe un VP de Emilia Casas Baamonde. La decisión del TC fue otorgar parcialmente el amparo interesado por algunas de las agrupaciones electorales y, en consecuencia: reconocer su derecho a la participación política en los asuntos públicos, directamente o por medio de representantes. Restablecerlas en su derecho, anulando a tal fin las Sentencias de la Sala Especial del art. 61 LOPJ de 3 de mayo de 2003. Finalmente desestimar las restantes demandas.

\section{Sentencia 95/2003, de 22 de mayo (BOE de 10 de junio). Ponente: Jiménez Sánchez (Recurso de inconstitucionalidad).}

Preceptos constitucionales: 24.1.

otros:

Objeto: art. 2.a) en relación con el inciso que residan legalmente en España, de la Ley 1/1996, de 10 de enero, de asistencia jurídica gratuita.

Materias: Derecho a la tutela judicial efectiva.

Se cuestiona la expresión de la citada norma por entender que excluir del derecho a la asistencia jurídica gratuita a los extranjeros residentes en España de forma ilegal no respeta el contenido esencial del derecho fundamental a la tutela judicial efectiva. Con la actual regulación los extranjeros ilegalmente residentes en España sólo gozan de asistencia letrada y asistencia y representación gratuitas en los procesos penales y contencioso-administrativos referentes al derecho de asilo, quedando fuera de la cobertura las cuestiones relacionadas con su status personal. Se debe tener en cuenta que en aplicación de la ley de extranjería que contempla la sanción de expulsión no les habilita a pleitear gratuitamente, impidiendo, de hecho, a obtener la tutela judicial efectiva y conculcándose su derecho a obtener una resolución judicial sobre actuaciones administrativas que tan decisivamente afectan a la vida de estas personas. Convendrá recordar aquí la doctrina del TC sobre la conexión existente entre el derecho a la asistencia jurídica gratuita y el derecho a la tutela judicial efectiva. Las SSTC 183/2001 y 117/1998 consideraron que el art. $119 \mathrm{CE}$ consagra un derecho constitucional de carácter instrumental, cuya finalidad inmediata radica en permitir el acceso a la justicia, para interponer pretensiones u oponerse a ellas, tratando así de ase- 
gurar que ninguna persona quede procesalmente indefensa por carecer de recursos (STC 138/1988). El derecho reconocido en el art. 119 CE no es, lógicamente, absoluto e ilimitado y ha sido caracterizado como un derecho prestacional y de configuración legal, sin que esa amplia libertad de configuración, a su vez, pueda ser tampoco absoluta. Como ya se dijo en la STC 16/1994 existe un contenido constitucional indisponible que obliga a reconocer el derecho a la justicias gratuita necesariamente a quienes acrediten insuficiencia de recursos para litigar (STC 117/1998). Las SSTC 99/1985 y 115/1987, han reconocido a los extranjeros, con independencia de su situación jurídica, la titularidad del derecho a la tutela judicial efectiva. El no reconocimiento, a su vez, de la asistencia jurídica gratuita supone una vulneración del derecho a la tutela judicial efectiva del que son titulares todas las personas, vulneración que resulta de la propia norma legal y que, por consiguiente, debe ser apreciado el vicio de inconstitucionalidad denunciado. Finalmente, conviene precisar que la expresión residan en (España) habrá de entenderse referida a la situación puramente fáctica de los que se hallan en territorio español.

VOTO PARTICULAR (Conde Martín de Hijas): Se disiente por considerar que no se produce la vulneración apreciada del art. 24 CE en la limitación de la Ley $1 / 1996$. No hay base constitucional para una identificación entre español y extranjero como la que se deduce de la Sentencia. No es incontrovertible que el derecho a la tutela corresponda por igual a españoles y extranjeros. La Sentencia se ha construido sobre la base de una ampliación del contenido del derecho a la tutela judicial efectiva, con el que se disiente. Se ha forzado el contenido del art. 24, incluyendo en él contenidos, como el derecho a la asistencia gratuita, que están ausentes del mismo. Se disiente, en suma, al considerar que la Sentencia constituye un exceso en la interpretación de la Constitución y supone, además, la asunción por parte del Tribunal de un papel de legislador que no le corresponde.

(García-Calvo y Montiel): Se disiente en la medida en que se considera que con la decisión adoptada se pueden generar situaciones abusivas de inasumible coste presupuestario y social. Se considera que el número de los afectados y el tipo de personas no tendrían ni siquiera el derecho a la tutela judicial, a la que se quiere conectar el derecho a la asistencia jurídica gratuita. Se traerá a colación la STC 12/1998 que reconoce la existencia de limitaciones en el acceso a la justicia por parte de aquellos que tienen derecho a la asistencia jurídica gratuita, límite que se ha considerado basado en una finalidad constitucional legítima, razonable y proporcionada. Asimismo se disiente, en la línea del VP anterior por considerar una extralimitación de las funciones del TC en este caso concreto. El derecho a la asistencia jurídica gratuita no forma parte del derecho a la tutela judicial efectiva y por ello se manifiesta el disentimiento.

(Rodríguez-Zapata Pérez): La interpretación de la Constitución que se hace en el FJ $7^{\circ}$ es indeterminada e imprecisa en su alcance. La exigencia de 
igualdad o puede ser entendida necesariamente como obligación de identidad. El estatuto de extranjería plantea cuestiones diferentes de las que se producen en el seno del estatuto de ciudadanía, la igualdad en la atribución o titularidad del derecho a la tutela judicial efectiva no implica excluir una regulación legislativa distinta del beneficio de justicia gratuita siempre que se ajuste a cánones de proporcionalidad y razonabilidad.

\section{ORGANIZACIÓN TERRITORIAL DEL ESTADO}

\section{A. Comunidades Autónomas.}

\section{B.2. Competencias.}

1. Sentencia 72/2003, de 10 de abril (BOE de 13 de mayo). Ponente: Rodríguez-Zapata Pérez (Recursos de inconstitucionalidad acumulados).

Preceptos constitucionales: 149.1.18풀 DA Tercera.

otros:

Objeto: Diversas disposiciones reglamentarias de carácter tributario sobre vehículos a motor

Materias: Régimen económico y fiscal de Canarias. Procedimiento administrativo común.

Se reivindica la competencia en materia de procedimiento administrativo para el desarrollo reglamentario de los tributos integrantes del régimen económico-fiscal de Canarias. De forma subsidiaria se reclama la competencia autonómica de gestión de los tributos cedidos. Los argumentos sobre los que se basa la reivindicación son: en primer lugar, la propia DA Tercera CE que recoge la existencia del régimen económico y fiscal de Canarias y cuyo reconocimiento debe implicar implícitamente la competencia para la regulación y gestión de los procedimientos tributarios y de los procedimientos económico-administrativos relacionados con la totalidad de los tributos integrados en dicho régimen. En segundo lugar, el art. 32.3 del Estatuto Canario (ECan) que atribuye a la Comunidad Autónoma la competencia para el desarrollo legislativo y ejecución en materia de normas de procedimiento económico administrativo y fiscal, así como para la regulación de los procedimientos de gestión, liquidación, recaudación, inspección y revisión. El citado precepto del ECan debe ser interpretado a la luz de lo establecido en el art. 149.1.18, en cuya virtud, al Estado le correspondería la legislación ge- 
neral sobre el procedimiento administrativo común, a la Comunidad Autónoma su desarrollo y ejecución, en la medida en que el impuesto controvertido está integrado en el régimen canario la competencia para desarrollarlo y gestionarlo corresponderá asimismo a la Comunidad Autónoma. En tercer lugar, la DA Cuarta LOFCA que establece la necesidad de tener en cuenta el peculiar régimen fiscal de Canarias al regular su régimen económico y fiscal. Finalmente, la atribución por parte de la Ley de Impuestos Especiales del rendimiento del Impuesto a la Comunidad Autónoma, debe entenderse que atribuye a ésta asimismo la competencia autonómica de gestión tributaria sobre la base del principio de los apoderamientos implícitos e integridad competencial. El TC considera que son aquí de aplicación sus consideraciones de la STC 16/2003 (véase el número anterior de esta Revista), a tenor de las cuales de ninguna de las normas citadas se deduce que la gestión del Impuesto especial sobre determinados medios de transportes sea una competencia de la titularidad de la CAC, ni la CE ni la LOFCA atribuyen competencias, limitándose exclusivamente a reconocer la existencia de un régimen especial en el archipiélago. A igual conclusión debe llegarse a la luz del citado art. 74 de la Ley de Impuestos Especiales, que se limita a atribuir el rendimiento del tributo, sin que quepa deducir competencia implícita alguna. Sí se encuentra ésta en el citado art. 34.14 ECan donde se establece que corresponde a la Comunidad Autónoma el desarrollo legislativo y la ejecución de las normas de procedimiento administrativo, económico-administrativo y fiscal que se derivan de las especialidades del régimen administrativo, económico y fiscal de Canarias. Se ha aducido asimismo por la Comunidad Autónoma que a la luz del art. 32.14 Ecan y el art. 149.1.18 interpretado a la luz de la Jurisprudencia del TC permite afirmar que la competencia para su desarrollo es de la Comunidad Autónoma. EL TC lo niega y trae en su apoyo la doctrina que se deriva de su STC 227/1988, distinguiendo entre procedimiento administrativo común y procedimiento $\mathrm{ra}$ tione materiae. La Constitución no reserva en exclusiva al Estado la regulación de estos procedimientos administrativos especiales. Aunque hay que entender que es una competencia conexas a las que el Estado ostenta para la regulación del régimen sustantivo de cada actividad. Así ya se interpretó en la citada Sentencia que cuando la competencia legislativa sobe una materia ha sido atribuida a una Comunidad Autónoma, a ésta cumple también la aprobación de las normas de procedimiento administrativo destinadas a ejecutarlas, si bien deberán respetarse en todo caso las reglas del procedimiento establecidas en la legislación del Estado dentro del ámbito de sus competencias (FJ 32 STC 227/1988 y FJ 8.b STC 98/2001). Se llega, por tanto, a la conclusión de que la Comunidad Autónoma no puede reivindicar la competencia para regular los procedimientos tributarios relativos a los tributos estatales integrantes del régimen económico fiscal de Canarias y, en particular el Impuesto especial sobre determinados medios de transportes. Es al Estado a quien corresponde su desarrollo y ejecución salvo que decida delegar esta función al amparo del art. 156.2 CE. Las especialidades que para Canarias se establecen en la Ley 
38/1992 no reclaman para la efectividad del impuesto controvertido singularidad procedimental alguna. Tampoco se aceptan por el TC las argumentaciones sobre la base de su doctrina en materia de gestión de subvenciones (STC 79/1992) que no guarda similitud alguna con el problema planteado; en los actuales conflictos se dilucidan las competencias de gestión de un tributo de titularidad estatal, sin que entre en juego título competencial autonómico alguno. Por lo que se refiere a la reclamación de carácter subsidiario, se ha reclamado la competencia de gestión del tributo cuestionado, de forma similar a como se hizo en relación con la cuestión debatida en la STC 16/2003. (Véase en el no anterior de esta Revista la STC 16/2003). En la línea ya desarrollada en la citada STC, se reitera que el impuesto cuestionado no se considera parte integrante del régimen económico y fiscal de Canarias, ni tiene tampoco la consideración de tributo cedido, aunque sí la tenga tras la aprobación del último sistema de financiación aprobado. La cesión no implica, en modo alguno, ni la transmisión de la titularidad sobre el mismo o sobre el ejercicio de las competencias inherentes, ni tampoco (STC 192/2000), el carácter irrevocable de la cesión. La regulación de todas las competencias financieras en relación con los tributos cedidos es materia de ley orgánica en virtud de lo dispuesto en el art. 157.3 CE. Puesto en relación con lo establecido en el art. 133 CE se puede afirmar que la potestad originaria del Estado no puede quedar enervada por disposición alguna de inferior rango y es evidente que la regulación de la materia tributaria relacionada con la cesión de tributos es objeto de ley orgánica. La conexión existente entre los arts. 133.1, 149.1.14 y 157.3 CE determina que se pueda afirmar la competencia del Estado para regular no sólo sus propios tributos, sino también el marco general de todo el sistema tributario, así como la delimitación de las competencias financieras de las Comunidades Autónomas, según ya quedó dicho en la referida STC 192/2000.

\section{Sentencia 81 / 2003, de 30 de abril (BOE de 17 de mayo). Ponente: Gay Mon- talvo (Cuestiones de inconstitucionalidad acumuladas).}

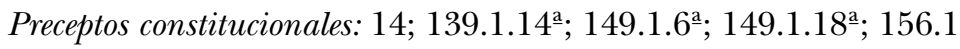

otros:

Objeto: Art. 17.3 de la Ley de la Comunidad valenciana 4/1984, de 13 de junio y art. 17.3 del TR de la Ley de Hacienda Pública de la Comunidad valenciana, aprobado por Decreto legislativo de 26 de junio de 1991.

Materias: Principio de igualdad ante la Ley; Hacienda general; Legislación procesal; Bases del régimen jurídico de las Administraciones Públicas; Coordinación entre las Haciendas estatal y autonómicas. 
Se plantean senda cuestiones de inconstitucionalidad por posible vulneración del art. $14 \mathrm{CE}$, así como por posible vulneración de los arts. 149.1.6ㅜㅜ; 149.1.14 ${ }^{\mathrm{a}}$ y 156.1 CE. Se considera que el art. 17.3 contradice la doctrina de la STC 110/1996 que fija el dies a quo del cómputo de plazo de los intereses de demora desde la fecha de la Sentencia dictada en primera instancia y no desde el día en que adquiera firmeza la resolución judicial, así como con los arts. 36.2 LGP y 1.2 LEC de 1881 que fijan como interés a satisfacer el legal del dinero y no el básico del Banco de España. También se aduce en relación con el citado 17.3 que contradice la competencia estatal en materia de legislación procesal, afecta a la competencia exclusiva del Estado relativa a las bases del régimen jurídico de las Administraciones Públicas, infringe el principio de coordinación con la hacienda estatal del art. $156 \mathrm{CE}$, pudiendo, finalmente, provocar una desigualdad contraria al art. $14 \mathrm{CE}$. Dos son las cuestiones a resolver: la determinación del dies a quo del devengo de los intereses, en primer lugar; en segundo, la relativa al cálculo de tales intereses. El contenido del art. 17.3 es contrario a lo dispuesto en el art. 921.4 LEC (1881); a lo establecido en el art. 45 LGP, que en atención a lo decidido por la STC 69/1996 debe ser interpretado en el mismo sentido que el art. 921 citado; y, por último, al art. 36.2 LGP que dispone que el interés de demora será el interés legal del dinero vigente el día en que venza el plazo señalado en el número anterior -desde el día siguiente a su vencimiento-, lo que vulneraría los arts. 14, 149.1.6; 149.1.14; 156 CE. Por lo que se refiere al cómputo del plazo, el precepto es susceptible de doble interpretación: puede entenderse que la declaración de firmeza de la resolución judicial que condena a su pago, supone el momento no sólo de su exigencia sino también el de su devengo; también pudiera interpretarse que esa declaración de firmeza implica sólo el presupuesto que habilita a su reclamación pero habiéndose producido su devengo en la fecha de la primera resolución judicial. En aplicación de lo decidido enla STC 9/1996 y 110/1996, sólo ésta segunda interpretación es compatible con la CE. El art. 45 debe ser leído a la luz del 921 LEC donde se contempla el denominado interés procesal, en relación con el cual, en atención a su carácter disuasorio, debe entenderse que el dies a quo se localiza en la fecha recaída en primera instancia dado que sólo esta conclusión se compadece con el art. $14 \mathrm{CE}$, ya que no se justifica en estos supuestos un tratamiento privilegiado para la Administración (SSTC 69/1996; 110/1996; 113/1996). A la luz de estas consideraciones el precepto debatido sólo se puede considerar constitucional si se interpreta en el sentido de la STC 69/1996, es decir, distinguiendo dos momentos: el comienzo del devengo de los intereses -que no es otro que el momento de la Sentencia dictada en primera instancia- y el de la exigibilidad de tales intereses que es el de la firmeza de la resolución judicial, debiendo, por tanto, ser desestimadas las cuestiones planteadas. Por lo que respecta a la segunda cuestión, debe ser estimada; la discordancia con el art. 36.2 LGP contraviene la CE como se desprende claramente de lo establecido la STC 
14/1986, en cuya aplicación se debe entender que la determinación cuantitativa del interés de demora ha de merecer un tratamiento unitario en todo el territorio nacional., lo que asimismo encuentra su fundamento en lo establecido en el art. 149.1.18 CE.. La regulación realizada por la Comunidad Autónoma también vulnera la competencia estatal prevista en el art. 149.1.18 al tratarse de una declaración normativa que excede del marco reservado a la Comunidad Autónoma (STC 14/1986); es asimismo contraria al art. 14 CE como ya advirtió la STC 110/1996, por lo que debe considerarse el precepto objeto de esta cuestión inconstitucional y nulo.

VOTO PARTICULAR (Rodríguez-Zapata Pérez): Se disiente en la medida en que se considera no cumplido un elemental principio de congruencia, en relación con las cuestiones planteadas. La competencia exclusiva del Estado en materia de legislación procesal excluye que las Comunidades Autónomas puedan crear ex novo normas de carácter procesal. El interés procesal tiene como finalidad resarcir los daños al acreedor por la tardanza en el cumplimiento de la obligación de pago. La naturaleza procesal de la norma que los fija determina con claridad que será de competencia estatal y no autonómica su regulación. Con ello se ha producido una manifiesta invasión competencial. 